\title{
Analysis of Density of Sintered Iron Powder Component Using the Response Surface Method
}

\author{
Prasanta Kumar Bardhan ${ }^{1}$, Suprs Patra ${ }^{2}$, Goutam Sutradhar ${ }^{3}$ \\ ${ }^{1}$ Department of Mechanical Engineering, JIS College of Engineering, Kalyani, India; ${ }^{2}$ Cwiss, IIT Kharagpur, West Bengal, India; \\ ${ }^{3}$ Department of Mechanical Engineering, Jadavpur University, Kolkata, India. \\ Email: pkbardhan@yahoo.com
}

Received March $18^{\text {th }}, 2010$; revised May $14^{\text {th }}, 2010$; accepted May $26^{\text {th }}, 2010$.

\begin{abstract}
The continued growth of ferrous powder metallurgy in automobile and others engineering application is largely dependent on the development of higher density materials and improved mechanical properties. Since density is a predominant factor in the performance of powder metallurgy components, it has been primarily considered for the present investigation. An experimental investigation have been undertaken in order to understand the variation of density with respect to the variation of process parameters viz., compaction load, sinter temperature and sintering time. The relation among the various process parameters with density has been observed. A mathematical model has been developed using second order response surface model (RSM) with central composite design (CCD) considering the above mentioned process parameters. The developed mathematical model would help in predicting the variation in density with the change in the level of different parameters influencing the density variation. This model also can be useful for setting of optimum value of the parameters for achieving the target density.
\end{abstract}

Keywords: Powder Metallurgy, Density, Sintering, Response Surface Model, Central Composite Design

\section{Introduction}

Growth of ferrous powder metallurgy (P/M) over the past few decades has been outstanding as this technology is providing itself as an alternate lower process cost to machining, casting, stamping, forging and other similar metal working technologies $[1,2]$. Along with that it also provides some outstanding advantages such as high material utilization, more refined microstructure that provides superior material properties as well as greater microstructure homogeneity. Above all the net shape making process by this $\mathrm{P} / \mathrm{M}$ method is a result of material design that provides consistent and minimal shrinkage after sintering from the originally compacted parts [3]. The use of the double press double sintering process is an accepted method for providing higher density parts. A low temperature presintering and a repress step are performed between the first compaction and final sintering steps [4-5]. In $\mathrm{P} / \mathrm{M}$ process a familiar method is double compaction and double sintering method although this process is well accepted due to achievement of high density samples; however it suffers from high costing which sometimes is not desirable. Another useful method in this regard is single compaction warm compaction process in which powders and tools are heated between $130^{\circ}$ and $150^{\circ}$ to achieve high density product. This method also provides increased green strength and reduced ejection forces $[5,6]$. To lower the production cost sometimes a relatively easier method is employed for the preparation of the $\mathrm{P} / \mathrm{M}$ products known as single compaction method where the desirable density can easily be achieved by controlling of sintering temperature and time. As sintering is a predominant factor for controlling the density of the P/M samples, variation of sintering time, temperature largely affects the density of the $\mathrm{P} / \mathrm{M}$ components [7-11]. In some cases a steam treatment or other secondary operations are necessary to meet specific usage requirement. In another version of the $\mathrm{P} / \mathrm{M}$ process, powder are pressed to a preform and hot forged immediately after sintering (Powder Forge-P/F process). The powder forged parts are comparable to conventional forged steel parts. $\mathrm{P} / \mathrm{M}$ process produce $95-98 \%$ of full density compare to $\mathrm{P} / \mathrm{F}$ process which produces $100 \%$ density [3].

The effects of different types of powder on density, age hardening on the pore closure and hardness of sintered iron and iron copper alloy have also been studied. The effect of compaction pressure and powder particle size on the pore structure and hardness of steam oxidized sintered iron have also been investigated [9]. When an imp- 
ermeable ferrous product is desirable, the sintered parts of high density can be steam treated to close the surface pores. It is also observed that the green density and sintered density is a function of powder type and compaction pressure [9].

Albeit, a large number of experimental investigations have been carried out, only few of them substantiated their observations with a theoretical model. However, present day industrial application demands comprehensive theoretical simulation before actual design. Considering these aspects we provided a theoretical model based on our experimental results. Present study examines the variation of density $\left(\mathrm{R}_{1}\right)$ as a function of process parameters (compactionload $\mathrm{x}_{1}$, sintering temperature $\mathrm{x}_{2}$, and sintering time $\mathrm{x}_{3}$ ) of sintered iron $\mathrm{P} / \mathrm{M}$ components. The samples were produced by changing the process parame- ters as per the design of experiment (DOE) and the resp- onse surface methodology (RSM) has been used to plan and analyze the density. The experimental plan adopts the face-centered central composite design (CCD). A second order response surface model (RSM) has been used to develop a predicting equation of density based on the data collected by a statistical design of experiments [12-14]. The analysis of variation (ANOVA) shows that the observed data fits well into the assumed second order RSM model. It is worth mentioning that this model is one of the most widely used methods to solve the optimization problem in manufacturing technology [10]. In the experiment, porosity of the samples, compacted and sintered under different conditions were investigated by the optical microscope [7]. It is found that porosity of the samples decreases with the increase of compaction load, sintering temperature and sintering time.

\section{Experimental Procedures}

The iron powder used in the present study was supplied by Kawasaki Steel Corporation Chiba Works, chiba, Japan. The said company has clarified chemical analysis and particle size distribution of the above powder material. The data has shown in Tables 1 and 2.

The iron powder was compacted in a closed cylindrical die using 120 Ton hydraulic press (Lawrence \& Mayo) for green stage product. During compaction, the die was lubricated with $\mathrm{Zn}$-stearate. The sintering process was carried out in a vacuum furnace of capacity $\left(1450^{\circ} \mathrm{C}\right)$
Table 1. Chemical Analysis of iron powder (weight\%)

\begin{tabular}{ccccccc}
\hline $\mathrm{C}$ & $\mathrm{Si}$ & $\mathrm{Mn}$ & $\mathrm{P}$ & $\mathrm{S}$ & $\mathrm{O}$ & $\mathrm{Fe}$ \\
\hline 0.001 & 0.02 & 0.17 & 0.013 & 0.010 & 0.129 & Balance \\
\hline
\end{tabular}

Table 2. Powder Properties. Apparent Density (gm/cc): 2.94; Flow (s/50gm): 24.7. Sieve Distribution

\begin{tabular}{ccc}
\hline Sieve Number & Size & Cumulative wt $\%$ \\
\hline$+100 \#$ & $>150 \mathrm{um}$ & 8.5 \\
$+150 \#$ & $>106 \mathrm{um}$ & 20.1 \\
$+200 \#$ & $>75 \mathrm{um}$ & 22.9 \\
$+250 \#$ & $>63 \mathrm{um}$ & 9.5 \\
$+325 \#$ & $>45 \mathrm{um}$ & 16.8 \\
$-325 \#$ & $<45 \mathrm{um}$ & 22.2 \\
\hline
\end{tabular}

using argon as an inert gas.

One of the major objectives of present investigations is to shade light on the density of the compacted sintered samples. In this context 60 different $\mathrm{P} / \mathrm{M}$ components (dia$25 \mathrm{~mm}$ ) were produced according to design of experiment (DOE). Related density $\left(\mathrm{R}_{1}\right)$ of these samples were measured by hydrostatic weighing method against the variation of controllable process variables like compaction load $\left(\mathrm{x}_{1}\right)$, sintering time $\left(\mathrm{x}_{3}\right)$ and sintering temperature $\left(\mathrm{x}_{2}\right)$. The results obtained through the experiments are given in Tables 3 and $\mathbf{4}$ and the available data have been analyzed by response surface method using Minitab software (version 14).

From the results of ANOVA a mathematical model has been proposed for the evaluation of density, $\mathrm{R}_{\mathrm{CCD}}$ (Density) of the powder metallurgy components. The proposed model is expressed as

$$
\begin{aligned}
\mathbf{R}_{\mathbf{C C D}}(\text { Density })= & -0.820967+0.218738 \mathrm{x}_{1} \\
& +0.008407 \mathrm{x}_{2}-0.571286 \mathrm{x}_{3} \\
& +0.007148 \mathrm{x}_{1}{ }^{2}-0.000002 \mathrm{x}_{2}{ }^{2} \\
& +0.064705 \mathrm{x}_{3}{ }^{2}-0.000333 \mathrm{x}_{1} \mathrm{x}_{2} \\
& -0.020574 \mathrm{x}_{1} \mathrm{x}_{3}+0.000767 \mathrm{x}_{2} \mathrm{x}_{3}
\end{aligned}
$$

\section{Results and Discussion}

In the present study iron powders, sintered at various tem-

\begin{tabular}{|c|c|c|c|c|c|c|c|c|}
\hline \multirow{2}{*}{$\begin{array}{c}\text { Process parameters } \\
\text { (Independent variables) }\end{array}$} & \multicolumn{2}{|c|}{ Symbols } & \multicolumn{6}{|c|}{ Levels } \\
\hline & Actual & Coded & & Actual & & & Coded & \\
\hline Compaction load (Ton) & $\mathrm{z}_{1}$ & $x_{1}$ & 17.66 & 20.075 & 26.49 & -1 & 0 & +1 \\
\hline Sintering temperature $\left({ }^{\circ} \mathrm{C}\right)$ & $\mathrm{z}_{2}$ & $x_{2}$ & 975 & 1050 & 1125 & -1 & 0 & +1 \\
\hline Sintering time ( $\mathrm{hrs}$ ) & $\mathrm{z}_{3}$ & $x_{3}$ & 1 & 1.5 & 2 & -1 & 0 & +1 \\
\hline
\end{tabular}
perature and time are investigated. The samples are compacted under different load range (14.6 ton-29.49 ton) according to the design of experiment (DOE).

Table 3. Symbols, levels and values of process parameters 
Table 4. Observed Density—values for different settings of process parameters based on $2^{3}$ full factorial design

\begin{tabular}{|c|c|c|c|c|c|c|c|}
\hline \multirow{2}{*}{$\begin{array}{l}\text { Sl. } \\
\text { No. }\end{array}$} & \multicolumn{3}{|c|}{ Coded Value of Parameters } & \multicolumn{3}{|c|}{ Actual Value of Parameters } & \multirow{2}{*}{$\frac{\text { Response variables } \mathrm{R}_{1}}{\text { Density }\left(\mathrm{g} / \mathrm{cm}^{3}\right)}$} \\
\hline & $\mathrm{x}_{1}$ & $\mathrm{x}_{2}$ & $\mathrm{x}_{3}$ & Compaction load. (Ton) & Sintering. Temp. $\left({ }^{\circ} \mathrm{C}\right)$ & Sintering. Time (Hrs.) & \\
\hline 1 & -1 & -1 & -1 & 17.66 & 975 & 1 & 6.07 \\
\hline 2 & 1 & -1 & -1 & 26.49 & 975 & 1 & 7.78 \\
\hline 3 & -1 & 1 & -1 & 17.66 & 1125 & 1 & 6.00 \\
\hline 4 & 1 & 1 & -1 & 26.49 & 1125 & 1 & 6.87 \\
\hline 5 & -1 & -1 & 1 & 17.66 & 975 & 2 & 6.07 \\
\hline 6 & 1 & -1 & 1 & 26.49 & 975 & 2 & 7.78 \\
\hline 7 & -1 & 1 & 1 & 17.66 & 1125 & 2 & 6.00 \\
\hline 8 & 1 & 1 & 1 & 26.49 & 1125 & 2 & 6.74 \\
\hline 9 & -1.6818 & 0 & 0 & 14.65 & 1050 & 1.5 & 5.94 \\
\hline 10 & 1.6818 & 0 & 0 & 29.50 & 1050 & 1.5 & 7.84 \\
\hline 11 & 0 & -1.6818 & 0 & 22.08 & 923.87 & 1.5 & 6.46 \\
\hline 12 & 0 & 1.6818 & 0 & 22.08 & 1176.13 & 1.5 & 6.39 \\
\hline 13 & 0 & 0 & -1.6818 & 22.08 & 1050 & 0.659 & 6.38 \\
\hline 14 & 0 & 0 & 1.6818 & 22.08 & 1050 & 2.341 & 6.53 \\
\hline 15 & 0 & 0 & 0 & 22.08 & 1050 & 1.5 & 6.38 \\
\hline 16 & 0 & 0 & 0 & 22.08 & 1050 & 1.5 & 6.50 \\
\hline 17 & 0 & 0 & 0 & 22.08 & 1050 & 1.5 & 6.50 \\
\hline 18 & 0 & 0 & 0 & 22.08 & 1050 & 1.5 & 6.60 \\
\hline 19 & 0 & 0 & 0 & 22.08 & 1050 & 1.5 & 6.50 \\
\hline 20 & 0 & 0 & 0 & 22.08 & 1050 & 1.5 & 6.50 \\
\hline 21 & -1 & -1 & -1 & 17.66 & 975 & 1 & 6.07 \\
\hline 22 & 1 & -1 & -1 & 26.49 & 975 & 1 & 7.93 \\
\hline 23 & -1 & 1 & -1 & 17.66 & 1125 & 1 & 6.00 \\
\hline 24 & 1 & 1 & -1 & 26.49 & 1125 & 1 & 7.75 \\
\hline 25 & -1 & -1 & 1 & 17.66 & 975 & 2 & 6.15 \\
\hline 26 & 1 & -1 & 1 & 26.49 & 975 & 2 & 7.79 \\
\hline 27 & -1 & 1 & 1 & 17.66 & 1125 & 2 & 6.00 \\
\hline 28 & 1 & 1 & 1 & 26.49 & 1125 & 2 & 7.74 \\
\hline 29 & -1.6818 & 0 & 0 & 14.65 & 1050 & 1.5 & 5.89 \\
\hline 30 & 1.6818 & 0 & 0 & 29.50 & 1050 & 1.5 & 8.04 \\
\hline 31 & 0 & -1.6818 & 0 & 22.08 & 923.87 & 1.5 & 6.38 \\
\hline 32 & 0 & 1.6818 & 0 & 22.08 & 1176.13 & 1.5 & 6.39 \\
\hline 33 & 0 & 0 & -1.6818 & 22.08 & 1050 & 0.659 & 6.38 \\
\hline 34 & 0 & 0 & 1.6818 & 22.08 & 1050 & 2.341 & 6.53 \\
\hline 35 & 0 & 0 & 0 & 22.08 & 1050 & 1.5 & 6.38 \\
\hline 36 & 0 & 0 & 0 & 22.08 & 1050 & 1.5 & 6.50 \\
\hline 37 & 0 & 0 & 0 & 22.08 & 1050 & 1.5 & 6.50 \\
\hline 38 & 0 & 0 & 0 & 22.08 & 1050 & 1.5 & 6.50 \\
\hline 39 & 0 & 0 & 0 & 22.08 & 1050 & 1.5 & 6.50 \\
\hline 40 & 0 & 0 & 0 & 22.08 & 1050 & 1.5 & 6.50 \\
\hline 41 & -1 & -1 & -1 & 17.66 & 975 & 1 & 6.07 \\
\hline 42 & 1 & -1 & -1 & 26.49 & 975 & 1 & 8.02 \\
\hline 43 & -1 & 1 & -1 & 17.66 & 1125 & 1 & 6.00 \\
\hline 44 & 1 & 1 & -1 & 26.49 & 1125 & 1 & 7.79 \\
\hline 45 & -1 & -1 & 1 & 17.66 & 975 & 2 & 6.15 \\
\hline 46 & 1 & -1 & 1 & 26.49 & 975 & 2 & 7.79. \\
\hline 47 & -1 & 1 & 1 & 17.66 & 1125 & 2 & 6.00 \\
\hline 48 & 1 & 1 & 1 & 26.49 & 1125 & 2 & 7.77 \\
\hline 49 & -1.6818 & 0 & 0 & 14.65 & 1050 & 1.5 & 6.06 \\
\hline 50 & 1.6818 & 0 & 0 & 29.500 & 1050 & 1.5 & 7.79 \\
\hline 51 & 0 & -1.6818 & 0 & 22.08 & 923.87 & 1.5 & 6.38 \\
\hline
\end{tabular}


Table 1 continued

\begin{tabular}{|c|c|c|c|c|c|c|c|}
\hline 52 & 0 & 1.6818 & 0 & 22.08 & 1176.13 & 1.5 & 6.39 \\
\hline 53 & 0 & 0 & -1.6818 & 22.08 & 1050 & 0.659 & 6.38 \\
\hline 54 & 0 & 0 & 1.6818 & 22.08 & 1050 & 2.341 & 6.53 \\
\hline 55 & 0 & 0 & 0 & 22.08 & 1050 & 1.5 & 6.38 \\
\hline 56 & 0 & 0 & 0 & 22.08 & 1050 & 1.5 & 6.50 \\
\hline 57 & 0 & 0 & 0 & 22.08 & 1050 & 1.5 & 6.50 \\
\hline 58 & 0 & 0 & 0 & 22.08 & 1050 & 1.5 & 6.50 \\
\hline 59 & 0 & 0 & 0 & 22.08 & 1050 & 1.5 & 6.50 \\
\hline 60 & 0 & 0 & 0 & 22.08 & 1050 & 1.5 & 6.50 \\
\hline
\end{tabular}

Figure 1 shows the microstructures of $\mathrm{P} / \mathrm{M}$ samples sintered at fixed temperature $\left(1050^{\circ} \mathrm{C}\right)$ and for fixed sintering time $(1.5 \mathrm{hrs}$.) under different compaction load. The white portion of the figure indicates iron grains and the black portions indicate porous area of the specimen. From the figure it is quite evident that with gradual increase of compaction load the porosity of the samples gradually decreases. Similar behavior is also observed with the variation of sintering time and sinter temperature, the porosity changes (not shown in figure). Decrease in porosity would increase the density. That phenomenon actually reflected in the Figure 2.

Variation of density against sintering temperature and compaction load is presented in Figure 2. The figure exhibits an increasing tendency in density due to change in sintering temperature from $975^{\circ} \mathrm{C}$ to $1176^{\circ} \mathrm{C}$ and compaction load from 14.65 Ton to 29.50 Ton at a fixed sintering time of $1.5 \mathrm{hrs}$. Identical nature of variation is noted in simultaneous increase of compaction load and sintering time. This observation is illustrated in Figure 3.

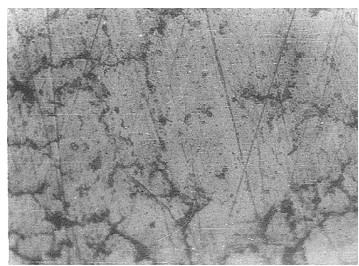

(a)

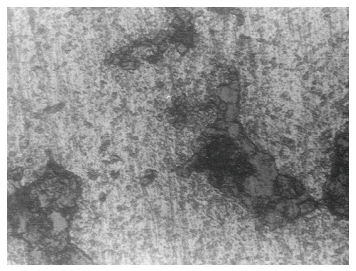

(c)

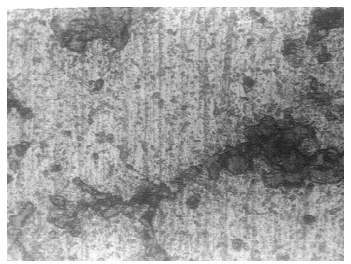

(b)

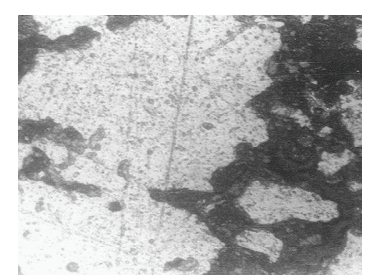

(d)
Figure 1. Microstructure of the iron $P / M$ specimen at different load (Original Photographs at $700 \times$ ). (a) Compaction load 29.50 Ton, Sintering temperature $1050^{\circ} \mathrm{C}$ Sintering time $1.5 \mathrm{hrs}$; (b) Compaction load 26.49 Ton, Sintering temperature $1050^{\circ} \mathrm{C}$, Sintering time $1.5 \mathrm{hrs}$; (c) Compaction load 22.08 Ton, Sintering temperature $1050^{\circ} \mathrm{C}$, Sintering time 1.5 hrs; (d)compaction load 17.66 Ton, Sintering temperature $1050^{\circ} \mathrm{C}$, Sintering time $1.5 \mathrm{hrs}$
In Figure 3, Compaction load has been altered between 14.65 Ton to 29.50 Ton and sintering time has been changed between 0.6 to $2.3 \mathrm{hrs}$ at invariant sintering temperature of $1050^{\circ} \mathrm{C}$. The response variable under consideration shows a completely diverse nature when it is plotted against sintering temperature and sintering time at a fixed compaction load of 22.08 Ton (Figure 4). In this case, the range of variation of the parameters is similar to that of previous two cases. It is worth mentioning, in all the cases the hold values are mean value of the range of variation corresponding to each variable. Average values are preferred because of the inherent nature of the RSM model.

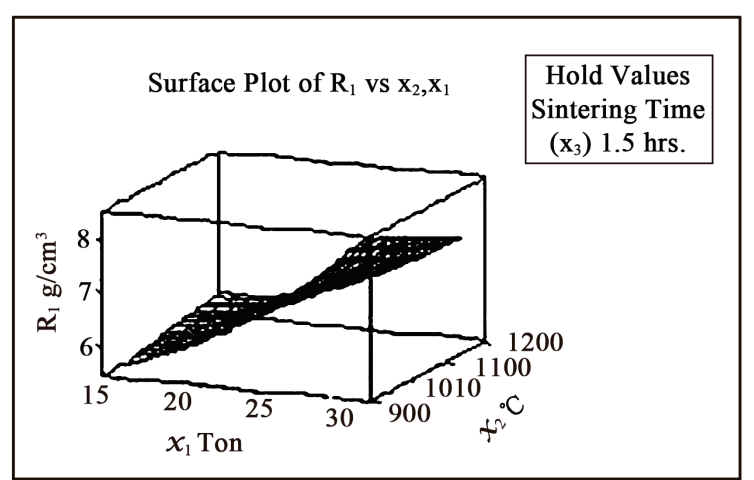

Figure 2.Surface Plot of density $\left(R_{1}\right)$ Vs. compaction load $\left(x_{1}\right)$ and sintering temperature $\left(x_{2}\right)$ for a fixed value of sintering time $\left(x_{3}\right)$

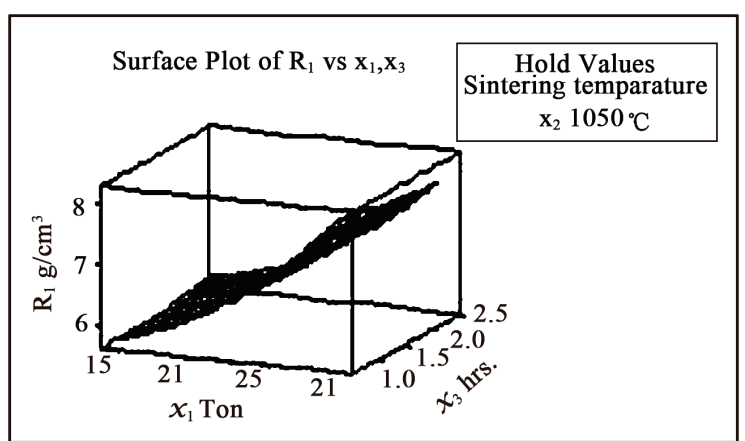

Figure 3. Surface Plot of density $\left(R_{1}\right)$ Vs. compaction load $x_{1}$ and sintering time ( $\left.x_{3}\right)$ for a fixed value of sintering temperature $\left(\mathbf{x}_{2}\right)$ 
Figure 2 and Figure 3 demonstrate an interesting feature. A closure look at the figures exhibit that at high enough compaction load role of temperature variation is not very prominent. However, role of temperature variation is quite evident in Figure $\mathbf{4}$ where the densification parameter is negative which clearly confirms compact swelling of the material. Table 5 presents the ANOVA (Analysis of variances) for the second order response surface equations, which quite clearly shows that second order response surface model fit well into the observed data. Observed density data and the predicted density data are depicted in Figure 5.

The figure shows that the experimental data resembles well with the predicted data. A comparative graph has been made between the predicting values of density with the observed values of densities. It is observed that the predicted values are mostly matching with the observed values with $10-15 \%$ error, which is accepted for any predicting analysis. It may be concluded that our predicting values is quite in sequence with the actual values. This is also evident from the findings that co-efficient of deter mination (R-Square) value is $89.8 \%$. Hence, it may be concluded that the prediction made by this developed model corroborates well with the experimental observations.

\section{Conclusions}

In the present study, a detail microstructure analysis has been made which confirms that the density of the $\mathrm{P} / \mathrm{M}$ product considerably increases with the increase in comp action load, sintering temperature and sintering time. The results obtained have been analyzed through the response surface model. A second order response surface method (RSM) has been used to develop a predicting equation of density based on the data collected by a statistical design of experiments known as central composite design (C$\mathrm{CD}$ ). The analysis of variance (ANOVA) shows that the observed data fits well into the assumed second order
RSM model. Pertinent microstructural analysis is also present.

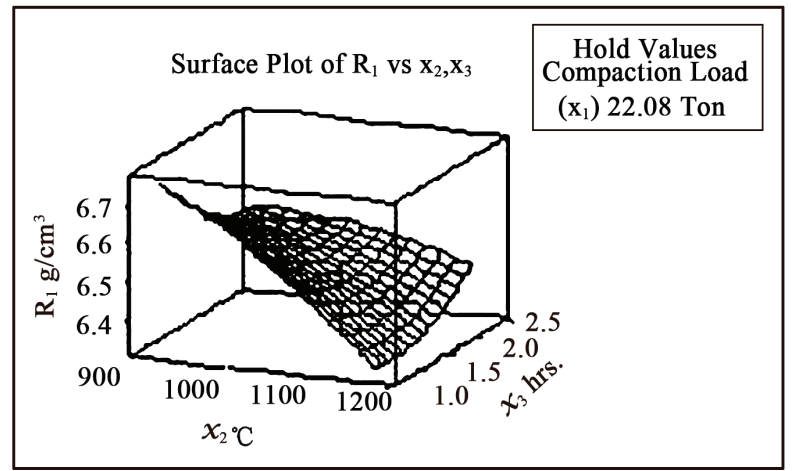

Figure 4. Surface Plot of density $\left(R_{1}\right)$ Vs. sintering temperature $\left(x_{2}\right)$ and sintering time $\left(x_{3}\right)$ for a fixed value of compaction load $\left(\mathbf{x}_{1}\right)$

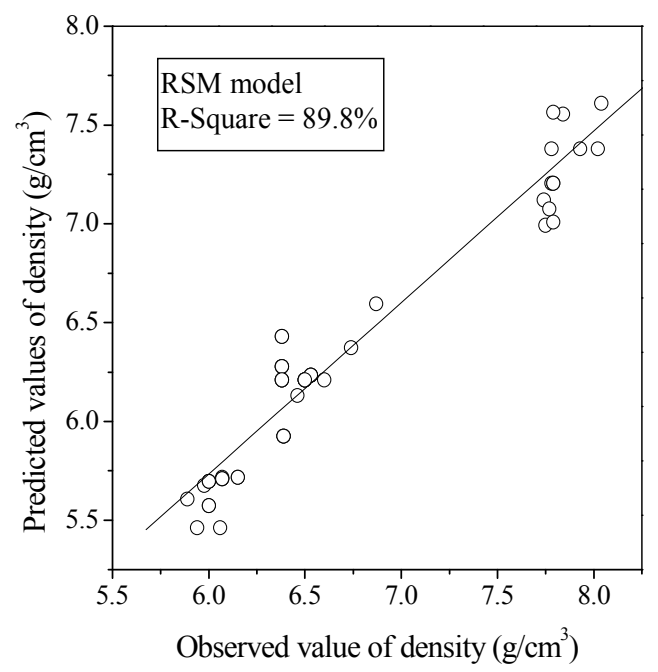

Figure 5. Plot between observed density data and predicted density for RSM model

Table 5. Analysis of Variance for $R_{1}$ (Density)

\begin{tabular}{|c|c|c|c|c|c|c|}
\hline Source & DF & Seq. SS & Adj. SS & Adj. MS & $\mathbf{F}$ & $\mathbf{P}$ \\
\hline Regression & 9 & 17.86968 & 17.86968 & 1.98552 & 39.85 & 0.000 \\
\hline Linear & 3 & 16.6457 & 0.09896 & 0.03299 & 0.66 & 0.579 \\
\hline Square & 3 & 0.8621 & 0.86206 & 0.28735 & 5.77 & 0.002 \\
\hline Interaction & 3 & 0.3619 & 0.36195 & 0.12065 & 2.42 & 0.077 \\
\hline Residual Error & 50 & 2.4911 & 2.49111 & 0.04982 & & \\
\hline Lack-of-Fit & 5 & 0.5991 & 0.59906 & 0.11981 & 2.85 & 0.026 \\
\hline Pure Error & 45 & 1.8920 & 1.89205 & 0.04205 & & \\
\hline Total & 59 & 20.3608 & & & & \\
\hline
\end{tabular}

DF: Degrees of freedom, SS: Sum of Square, MS: Mean Square of variation, F: F-test, P: Value of probability $\mathrm{R}-\mathrm{Sq}=89.8 \%$ 


\section{Acknowledgements}

Authors are very much grateful to All India Council For Technical Education, New Delhi [F. No. 8021 /RID/ NPROJ/R\&D-174/2002-03/ (Revalidated 2003-2004) for funding this Project. Authors also like to acknowledge their sincere thanks to M/S Kawasaki Steel Corporation Chiba Works, Chiba, Japan for sending $4 \mathrm{Kg}$ iron Powder along with the certificate of chemical analysis free of cost for this study. Authors also acknowledge the facilities received from the Metal Forming Laboratory, Mechanical Engineering Department. Jadavpur University, Kolkata, India.

\section{REFERENCES}

[1] R. M. German, "Powder Metallurgy of Iron and Steel," John Willy \& Sons, New York, 1998.

[2] G. S. Upadhyaya, "Powder metallurgy Technology," Cambridge International Science Publishing, Cambridge, 1997.

[3] K. S. Narasimhan, "Recent Advances in Ferrous Powder Metallurgy," Advanced Performance Materials, Vol. 3, No. 1, 1996, pp. 7-27.

[4] H. Rutz, J. Khanuja and S. Kassam, "Single Compaction to Active High Density in Ferrous P/M Materials in Automatic Applications," PM2TEC'96 World Congress, Washington, D.C., 1996.

[5] H. G. Rutz and F. G.Hanejko, "The Application of Worm Compaction to High Density Powder, Metallurgy Parts," PM2TEC'97 International Conference on Powder Metallurgy \& Particulate Materials, Chicago, 1997.

[6] H. G. Rutz and F. G. Hanejko, "High Density Processing of High Performance Ferrous Materials. Advances in Powder Metallurgy and Particulate Materials," Metal Powder In- dustries Federation, Princeton, Vol. 5, 1994, p. 117.

[7] L. A. Dobrzanshi, J. Otereba, M. G. Actis and M. Rosso, "Microstructural Characteristics and Mechanical Properties of Ni-Mo-(W) Steels," Journal of Achievements in Materials and Manufacturing Engineering, Vol. 18, 2006, p. 347.

[8] K. S. Naransimhan, "Sintering of Powder Mixtures and the Growth of Ferrous Powder Metallurgy," Materials Chemistry and Physics, Vol. 67, No. 1-3, 2001, pp. 56-65.

[9] W.-F. Wang, "Effect of Powder Type and Compaction Pressure on the Density, Hardness and Oxidation Resistance of Sintered and Steam Treated Steels," Journal of Materials Engineering Performance, Vol. 16, No. 5, 2007 , pp. 533-538.

[10] K.-Y. Kung, J.-T. Horng and K.-T. Chiang, "Material Removal Rate and Electrode Wear Ratio Study on the Powder Mixed Electrical Discharge Machining of Cobalt-Bonded Tungsten Carbide," International Journal of Advanced Manufacturing Technology, Vol. 40, No. 1-2, 2009, pp. 95-104.

[11] A. K. Eksi and A. H. Yuzbasioglu, "Effect of Sintering and Pressing Parameters on the Densification of Cold IsoStatically Pressed Al and Fe Powder," Materials \& Design, Vol. 28, No. 4, 2007, pp. 1364-1368.

[12] D. Chatterjee, B. Oraon, G. Sutradhar and P. K. Bose, "Prediction of Hardness for Sintered HSS Components Using Response Surface Method," Journal of Materials Processing Technology, Vol. 190, No. 1-3, 2007, pp. 123129.

[13] G. E. P. Boxes and N. R. Draper, "Emperical Model Building and Response Surfaces," Wiley, New York, 1987.

[14] D. C. Montgomery, "Design and Analysis of Experiments," John Wiley \& Sons, New York, 1991.

$\mathrm{R}_{1} \quad$ density of sintered iron component

Rccd Predicting equation of density of sintered iron component

$\mathrm{z}_{1} \quad$ actual value of Compaction load 